\title{
Corrigendum: Biocontrol genome deciphered
}

Dieter Haas

Nat. Biotechnol. 23, 823-824 (2005), corrected 27 March 2006

In the print version of this article and the version originally published online, there was an error in the order of incorporation of the amino acids into the final structure shown in Figure 1. The errors have been corrected in the PDF version of the article.

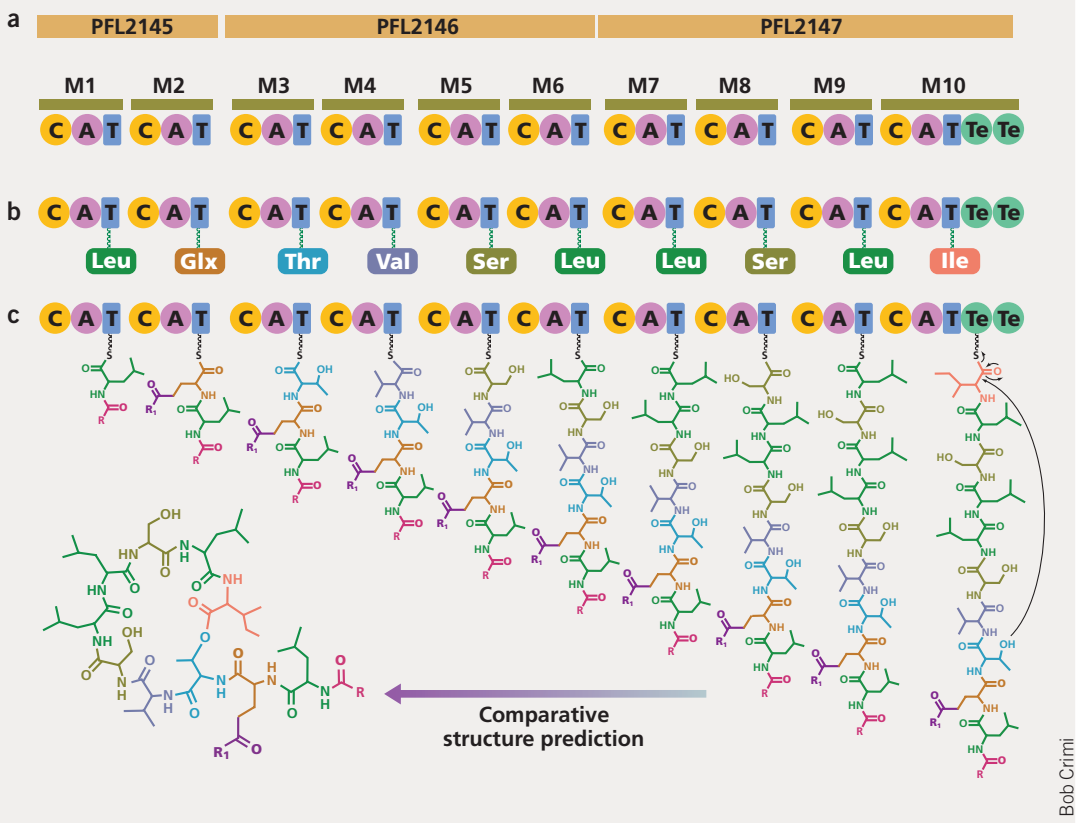

\section{Corrigendum: Complete genome sequence of the plant commensal} Pseudomonas fluorescens Pf-5

Ian T Paulsen, Caroline M Press, Jacques Ravel, Donald Y Kobayashi, Garry S A Myers, Dmitri V Mavrodi, Robert T DeBoy, Rekha Seshadri, Qinghu Ren, Ramana Madupu, Robert J Dodson, A Scott Durkin, Lauren M Brinkac, Sean C Daugherty, Stephen A Sullivan, Mary J

Rosovitz, Michelle L Gwinn, Liwei Zhou, Davd J Schneider, Samuel W Cartinhour, William C Nelson, Janice Weidman, Kisha Watkins, Kevin Tran, Hoda Khouri, Elizabeth A Pierson, Leland S Pierson III, Linda S Thomashow \& Joyce E Loper

Nat. Biotechnol. 23, 873-878 (2005), corrected 27 March 2006

In the print version of this article and the version originally published online, there is an error in Figure $3 \mathrm{c}$. The figure has been replaced with a corrected figure in the PDF version of the article.

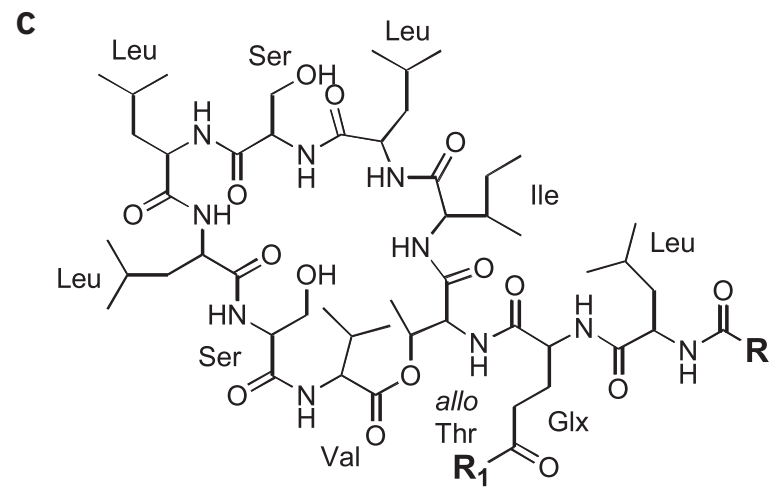

